\title{
BMJ Open A non-experimental study of oral anticoagulation therapy initiation before and after national patient safety goals
}

\author{
Christopher A Beadles, ${ }^{1,2,3}$ Kristen Hassmiller Lich, ${ }^{2}$ Anthony J Viera, ${ }^{4}$ \\ Sandra B Greene, ${ }^{1,2}$ M Alan Brookhart, ${ }^{5}$ Morris Weinberger ${ }^{2,3}$
}

To cite: Beadles CA, Hassmiller Lich K, Viera AJ, et al. A non-experimental study of oral anticoagulation therapy initiation before and after national patient safety goals. BMJ Open 2014;4: e003960. doi:10.1136/ bmjopen-2013-003960

- Prepublication history and additional material for this paper is available online. To view these files please visit the journal online (http://dx.doi.org/10.1136/ bmjopen-2013-003960)

Received 5 September 2013 Revised 20 January 2014 Accepted 21 January 2014

CrossMark

For numbered affiliations see end of article

Correspondence to Dr Christopher A Beadles; beadles@email.unc.edu

\section{ABSTRACT}

Objectives: The Joint Commission revised its National Patient Safety Goals (NPSGs) to include oral anticoagulation therapy (OAT) in 2008. We sought to examine the effect of including OAT in The Joint Commission's NPSGs on historically low rates of OAT initiation for individuals with incident atrial fibrillation (AF).

Setting: Southeastern state in the USA.

Participants: North Carolina State Health Plan claims data from 944500 individuals enrolled between 1 January 2006 and 31 December 2010, supplemented with data from the Area Resource File and Online Survey, Certification and Reporting data network. We evaluated OAT initiation before and after the 2008 NPSGs revisions in a retrospective cohort new user design with an $\mathrm{AF}$ intervention group and two control groups: a positive control-patients estimated to be at very high risk of thromboembolism (mechanical heart valve and pulmonary embolism); and a negative control - patients with very low perceived risk of thromboembolism (paroxysmal AF). We developed multivariable models using a difference-in-difference parameterisation. Effects were estimated with generalised estimating equations.

Primary outcome measure: OAT initiation, a binary outcome defined as having a prescription drug claim for warfarin within 30 days of the index claim.

Results: OAT initiation was low (26.8\%) for eligible individuals with incident AF in 2006-2008 but increased after NPSGs implementation $(31.7 \%$, $\mathrm{p}=0.022)$. OAT initiation was high but decreased in the positive control group ( $67.5 \%$ vs $62.0 \%, p=0.003$ ). Multivariate analysis resulted in a relative $11 \%(95 \% \mathrm{Cl}$ $(4 \%$ to $18 \%), p<0.01$ ) increase in OAT initiation for incident AF patients.

Conclusions: We document a substantial increase in guideline concordant OAT initiation in incident AF after the establishment of NPSGs, suggesting that regulatory healthcare agency initiatives can influence clinical practice.

\section{BACKGROUND}

Oral anticoagulation therapy (OAT) to reduce acute ischaemic stroke risk in patients with moderate-risk or high-risk atrial

\section{Strengths and limitations of this study}

- Privately insured cohort with 5 years claims data, extensive control variables and two control groups.

- Claims analysis; lacks individual race/ethnicity and socioeconomic status information; may not generalise to public insurance programmes (eg, Medicaid and Medicare).

- Non-experimental, pre-post two-group comparison design means that results cannot be interpreted as causal.

fibrillation (AF), typically with warfarin, has been recommended by guidelines from major organisations for nearly two decades. ${ }^{1}$ However, despite its benefit, OAT is often underutilised among eligible patients with $\mathrm{AF}^{2-8}$ Underutilisation may result from patient, physician and/or healthcare system factors. ${ }^{9-15}$

The Joint Commission is the nation's oldest and largest standards-setting and accrediting body in healthcare. Its primary purpose is to ${ }^{16}$ : "continuously improve healthcare for the public, in collaboration with other stakeholders, by evaluating healthcare organisations and inspiring them to excel in providing safe and effective care of the highest quality and value". To this end, the Joint Commission evaluates and accredits more than 19000 healthcare organisations and programmes in the USA. The Joint Commission accreditation is required for reimbursement from Medicare and many private health insurance companies. The Joint Commission established a National Patient Safety Goals (NPSGs) programme in 2002 to help accredited organisations address specific patient safety concerns. To oversee this task, it established the Patient Safety Advisory Group, a panel of nurses, physicians, pharmacists, risk managers, clinical engineers and other professionals who 
have hands-on experience in addressing patient safety issues in a wide variety of healthcare settings. This panel continuously evaluates and updates NPSGs to identify, prioritise and help address a broad range of emerging patient safety issues.

In 2008, the NPSGs were updated to include goals regarding OAT. The NPSGs concerning anticoagulation (specifically, NPSG 03.05.01) represent a change in the external environment, or natural experiment, intended to affect the healthcare system, most notably hospitals. They do not mandate that all eligible patients receive anticoagulation, but rather provide explicit guidelines and expectations for hospitals that provide anticoagulation therapy and/or long-term OAT to reduce the likelihood of patient harm associated with these therapies.

Achieving compliance with NSPGs may be moderated by a hospital's pre-existing resources and practice norms, as well as their willingness to invest in the infrastructure required to meet them. Hospitals with sufficient resources may be in compliance with regulatory requirements before or soon after they are established. Hospitals with fewer resources may take longer to become compliant with new regulatory requirements or attempt to avoid them altogether. In the case of OAT, hospitals may invest in resources to provide long-term outpatient management and monitoring for patients receiving OAT, for example, anticoagulation clinics. Providing anticoagulation clinics is thought to increase OAT initiation and OAT quality as community admitting physicians may be more likely to initiate OAT due to hospital regulatory requirements and the availability of additional resources to manage and monitor anticoagulation. ${ }^{14} 17$

However, hospitals may instead opt to minimise use of anticoagulants, discontinue anticoagulation clinics and elect not to initiate OAT in eligible patients, in the hope of avoiding increasing regulatory oversight and burden of compliance. In this case, hospital actions negatively influence OAT initiation via establishing clinical inertia (eligible patients often start OAT as inpatients) and the NPSGs (intended to prevent harm) may have an unintended effect in reducing OAT initiation for eligible patients. The precedent of newly developed policy achieving its proximal intended effects while creating larger downstream unintended effects is well-established. For example, pay-for-performance and organisational quality reporting initiatives have been met with unintended consequences in the experience of several countries. ${ }^{18-21}$ This can include unintended consequences of increased healthcare costs, ${ }^{22}$ reduced quality of unreported care ${ }^{21}$ and lower quality care among highest risk patients. ${ }^{18} 20$ Similarly, public reporting of outcomes data by provider for cardiac surgery in New York state led to subsequent high-risk patient aversion and higher cardiac surgery mortality rates in neighbouring states. ${ }^{23}$ Finally, the Center for Medicare and Medicaid Services (CMS) recently implemented a policy to withhold payment to hospitals for certain avoidable adverse events has also resulted in unintended consequences. ${ }^{24}$
Although the implementation of NPSGs is intended to improve healthcare quality (especially process-oriented measures), the Joint Commission's prior initiatives have had mixed success. For example, compliance with the Joint Commission guidelines for discharge instructions in patients with heart failure was associated with decreased readmission rates. ${ }^{25}$ Similarly, a positive relationship between adherence to the Joint Commission heart failure core measures and 1-year survival has been reported. ${ }^{26}$ However, other studies found no association between adherence to the Joint Commission heart failure core measures and mortality or readmission at $60-90$ days or at 1 year. ${ }^{27} 28$

We sought to determine the effect of the Joint Commission's anticoagulation NPSGs on OAT initiation. We hypothesised the NPSGs would increase OAT initiation among eligible patients hospitalised with incident $\mathrm{AF}$, but were keenly aware of the potential unintended negative influence of the NPSGs on OAT initiation. We also conducted sensitivity analyses to examine potential indirect effects of the NPSGs.

\section{METHODS}

\section{Data sources}

We used data from 1 January 2006 to 31 December 2010 from the North Carolina State Health Plan (NCSHP), a large self-funded insurance plan for the study. The NCSHP, administered by Blue Cross and Blue Shield of North Carolina, includes almost 700000 state employees, teachers, retirees and their dependents at any given time and approximately one million individuals are included in the 5-year study window. Approximately $10 \%$ of enrollees are retired non-Medicare participants, and $16 \%$ are retired Medicare beneficiaries. This claims structured database contains inpatient, outpatient and pharmacy records. Enrollee descriptors include unique encrypted member identification numbers, basic demographic information including age, gender, county and Zone Improvement Plan (ZIP) code of primary residence. Records include information about diagnoses, procedures, providers, charges and payments. The database also contains physician level characteristics which include provider ZIP code, type of provider and provider specialty if applicable. We linked the NCSHP database to hospital facility characteristics including accreditation as a primary stroke centre, hospital bed size and participation in a stroke quality improvement programme. Finally, we linked individual and facility counties with variables from the Area Resource File to concurrently analyse healthcare delivery at the patient, provider, hospital facility and county levels.

\section{Cohort selection rationale}

Our goal was to create three cohorts with varying levels of thromboembolism risk without receipt of OAT. Specifically we sought to create perceived high, medium and low thromboembolism risk cohorts, with the intent 
to use the high-risk and low-risk cohorts as positive and negative control groups, respectively. The incidence of thromboembolism in patients with mechanical heart valves is $4.4 / 100$ patient-years without anticoagulation and 1.0/100 patient-years with warfarin. ${ }^{29}$ Although the attributable risk of AF to ischaemic stroke increases dramatically with increasing age, the overall relative risk is approximately fivefold higher for ischaemic stroke among patients with $\mathrm{AF}^{30}$ Including all ages, the average annual risk of ischaemic stroke for individuals with $\mathrm{AF}$ is $2-4 \%$ per year (2-4 per 100 patient-years). ${ }^{29}$ OAT reduces this risk by $64 \% .^{31}$ Historically paroxysmal (intermittent) AF has been considered a lower risk for ischaemic stroke than mechanical heart valves and chronic $\mathrm{AF}^{32}{ }^{33}$ However, a signal of equivalent ischaemic stroke risk was apparent as early as 2000 in the Stroke Prevention in AF trial. ${ }^{34}$ Yet despite others confirming the elevated risk associated with paroxysmal $\mathrm{AF}^{32} 35$ major guidelines for primary prevention of stroke were not changed to include OAT for paroxysmal AF until 2006. ${ }^{29}$ Thus our inclusion of paroxysmal AF as a negative control group is based on historically perceived risk rather than actual risk of ischaemic stroke.

\section{Study sample}

We created three cohorts: (1) patients with new onset AF; (2) positive control patients who are estimated to be at high risk of thromboembolism (mechanical heart valve or significant venous embolism) and (3) negative control patients, often mistakenly perceived to have a very low risk of thromboembolism (paroxysmal AF). For all three cohorts, patients needed to be continuously enrolled in the NCSHP a minimum of 6 months prior to and 6 months following the qualifying index claim. Individuals with a prescription claim for warfarin more than 30 days prior to an index claim for any of the three cohorts were excluded due to a high probability of representing prevalent rather than incident conditions. Figure 1 provides a summary of cohort identification and determination of eligibility. Eligibility criteria for each cohort are described below.

Patients with new onset AF: We used either one inpatient diagnosis or two outpatient diagnoses within 12 months (International Classification of Disease 9th edition-Clinical Modification (ICD-9-CM) code 427.31) to identify individuals with AF. We designated the first outpatient AF claim or hospital admission as the date of entry into the cohort. The American College of Cardiology, the American College of Chest Physicians and the American Heart Association endorse the use of a risk-based score to identify individuals who will benefit from receiving OAT. CHADS2 is a commonly employed scoring system. ${ }^{36}$ Individuals receive one point for congestive heart failure, hypertension, age $>75$ years, and diabetes mellitus; they receive two points for any prior stroke or stroke symptoms. CHADS2 scores are readily generated using claims data (see web-only table A.1 for ICD-9-CM codes for these diagnoses). Based on current recommendations, ${ }^{31}$ we included all individuals meeting criteria for incident AF with a CHADS2 score $\geq 2$. To increase the precision of our estimates, we used ICD-9-CM codes to exclude individuals with $\geq 1$ relative contraindication to OAT from the incident $\mathrm{AF}$ or intervention cohort (see web-only table A.2 for contraindications and ICD-9-CM codes). Finally, to reduce the probability of including individuals with prevalent, rather than incident, AF, we excluded individuals with any AF-related claim in the 6 months preceding the index claim.

Perceived very high-risk patients (positive controls): this cohort includes individuals with either one inpatient diagnosis or two outpatient diagnoses within 12 months indicating a mechanical heart valve or significant thromboembolism (see web-only table A.3 for diagnoses and ICD-9-CM codes). The CHADS2 score was not applied to this cohort, as it is only validated in patients with AF. Finally, to reduce the probability of including individuals with prevalent conditions rather than incident mechanical heart valves or significant thromboembolism, we excluded individuals with any condition-related claim in the 6 months preceding the index claim.

Perceived low-risk patients (negative controls): individuals with either one inpatient diagnosis or two outpatient diagnoses within 12 months for paroxysmal AF (ICD-9-CM code 427.21) were included in the negative control cohort.

\section{Measures}

The primary dependent variable is OAT initiation, a binary outcome defined as having a prescription drug claim for warfarin within 30 days of the index claim. Index claims occurring in years 2006-2008 were
Figure 1 Selection of incident atrial fibrillation (AF), application of inclusion/exclusion criteria and identification of comorbid conditions. Key aspects of defining eligibility period, measurement of comorbid conditions and measurement of oral anticoagulation therapy (OAT) initiation are shown above.

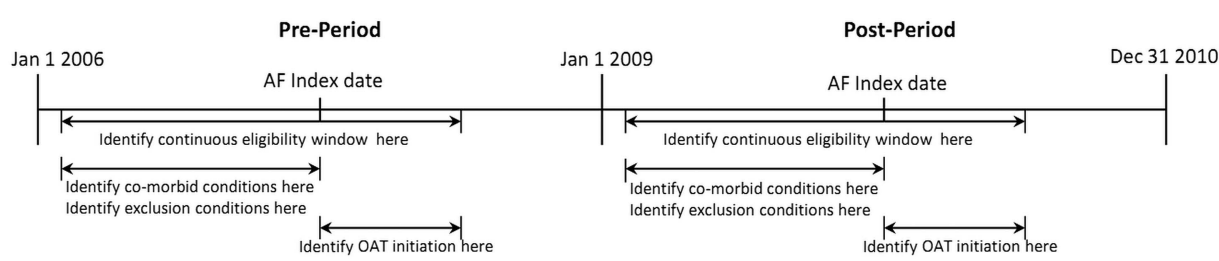


categorised as pre-NPSGs; index claims in 2009-2010 were assigned post-NPSGs status. The key explanatory variable is the interaction term between a binary indicator for prestatus/poststatus of the Joint Commission's NPSGs and a binary indicator variable for the incident $\mathrm{AF}$ cohort, which represents the difference-in-difference estimator. The difference-in-difference estimator is the pre-post difference in the treatment (AF cohort) group minus the pre-post difference in the control group (positive control cohort).

Control variables were created at the patient, county and facility levels. All control variables were identified a priori and measured in the baseline period or immediately prior to the index $\mathrm{AF}$ claim to mitigate potential confounding. Patient-level control variables include age, gender, Charlson Comorbidity Index, ${ }^{37}{ }^{38}$ CHADS2 score, rurality/urbanicity of residence, and number of outpatient visits to a primary care provider in the 30 days prior to the index claim. The Charlson Comorbidity Index, a widely used measurement of patient comorbidities, was categorised as $0,1,2,3-4$ and $\geq 5$. CHADS2 score was categorised as 2, 3-4 and $\geq 5$. Rurality/urbanicity of residence was categorised into rural, micropolitan or metropolitan as defined by the Area Resource File. ${ }^{39}$

County-level control variables included: race and ethnicity demographics, unemployment rate, per cent of persons below poverty line, median household income, a rolling 3-year average number of deaths from cerebrovascular disease, number of general practitioners and number of cardiovascular subspecialists in county, which were extracted from the Area Resource File. ${ }^{39}$

We specifically included several facility-level variables that were anticipated to have substantial influence in OAT initiation rates. These facility level control variables included: hospital primary stroke centre accreditation status as defined by CMS (binary variable for each time period); participation in 'Get with the Guidelines Stroke:' Program or North Carolina Stroke Care Collaborative, stroke care quality improvement programmes that include AF and OAT (binary variable for each time period); distance of hospital from enrollee residence; hospital bed size and rural/urban facility location. Get with the Guidelines Stroke participation was determined from the American Heart Association website (http://www.heart.org). Participation in the North Carolina Stroke Care Collaborative was provided by the organisation. We calculated distance as the straight line distance from the centroid of patient and hospital ZIP codes using SAS V.9.2. Hospital bed size was determined from the Online Survey, Certification and Reporting (OSCAR) data network maintained by the CMS.

\section{Statistical analysis}

We examined cohorts for differences in baseline covariates as well as differences within cohorts between preperiod and postperiod. Unadjusted rates of OAT initiation for each cohort were also examined. We then estimated the association between NPSGs and initiation of OAT among individuals with new onset AF using a difference-in-difference approach and multivariable regression equations. Differences in OAT initiation before and after the policy change for the control groups are attributed to a time effect. Subtracting the pre-post difference in the positive control cohort from the pre-post difference in the AF (treatment) cohort yields an estimate that is more robust to external factors and time effects. In practice the difference-in-difference estimate is created by interacting the treatment (in this case time) variable with a dummy variable indicating the treatment cohort. Thus we model the probability of OAT initiation using a log-Poisson model specified as:

$$
\operatorname{Pr}\left(\mathrm{OAT}_{\text {ift }}=1 \mid \mathrm{X}_{\mathrm{ift}}\right)=\log \mathrm{X} \beta
$$

with

$$
\mathrm{X} \beta=\beta_{0}+\beta_{1} \mathrm{AF}_{\mathrm{i}}+\beta_{2} \text { Post }_{\mathrm{i}}+\beta_{3}\left(\mathrm{AF}_{\mathrm{i}} \times \text { Post }_{\mathrm{i}}\right)+\beta_{4} \mathrm{X}_{\mathrm{i}}
$$

where $\mathrm{i}$ indicates the individual, OAT is the outcome variable, $\mathrm{AF}$ represents the cohort and Post indicates whether the index claim occurred pre (Post $=0)$ or post (Post=1) NPSGs implementation, and $\mathrm{X}$ is a vector of individual patient and facility control variables defined above. Facility level fixed effects are taken into account by clustering within facilities using the administrative hospital identification number and specifying an exchangeable within-group correlation structure. The coefficient that identifies the effect of interest is $\beta_{3}$, which estimates the effect of NPSGs on the probability of OAT initiation for patients with incident AF.

We estimated the parameters in the above model robustly using generalised estimating equation (GEE) methods in which we specified a Poisson error distribution. To account for within hospital correlation (eg, observations within hospital are not completely independent observations) we clustered on administrative hospital identification number by specifying the cluster variable during fitting of the GEE model and assumed an exchangeable within-group working correlation structure. ${ }^{40}$ Robust (sandwich estimation) SEs were estimated during model fitting, to account for underdispersion of the binary dependent variable in the context of a count distribution. ${ }^{41}$ We converted the coefficients to average marginal effects as absolute risk differences for ease of interpretation. All models were estimated in Stata V.11 (StataCorp, College Station, Texas, USA).

We conducted several sensitivity analyses. The first assessed potential measurement error in OAT initiation. The rise of many low-cost generic prescription drug programmes administered through major retailers has caused concern regarding under identification of generic drugs within pharmacy claims data. ${ }^{42}{ }^{43}$ Warfarin has been generic for several decades, and multiple generic formulations exist. While a claim for warfarin is specific for OAT initiation, it may be lacking 
somewhat in sensitivity. We created two alternative definitions for OAT initiation using claims for laboratory blood tests associated with blood coagulation or anticoagulation management claims (see web-only table A.4 for Current Procedural Terminology (CPT) codes and ICD-9-CM codes employed). The laboratory blood tests were hypothesised to represent a sensitive measure of OAT initiation that might have less specificity for OAT initiation as it is associated with the monitoring of the effect of warfarin, but is not specific to anticoagulation management alone.

The first alternative definition for OAT initiation combined: a pharmacy claim for warfarin; a claim for associated laboratory blood tests or a claim for OAT management. The second alternative definition excluded the pharmacy claim, utilising only the laboratory blood test and OAT management claims to define initiation. The next sensitivity analysis compared the effect of the policy on an inpatient only cohort (hypothesised to demonstrate the greatest effect), an outpatient only cohort, and a combined inpatient and outpatient cohort. The final set of sensitivity analyses involved an extensive evaluation of non-linear effects of included model covariates and additional county level covariates that could be hypothesised to affect the observed relationship between the policy change and observed OAT initiation rates.

\section{RESULTS}

\section{Descriptive findings}

We identified 2021 individuals for the AF cohort; 2708 individuals for the positive control cohort; and 606 individuals for the negative control cohort (table 1). Both control groups exhibited a decrease in proportion initiating OAT while the eligible AF cohort exhibited an increase $(0.268$ vs 0.317$)$. The relative OAT initiation pre-post difference (change in intervention minus change in control) for the eligible AF cohort was 0.104 and 0.081 in comparison to the positive and negative controls, respectively. OAT initiation in the AF group $(26.8 \%)$ was within range of previous observational studies. $^{44}$

Within specific cohorts, age remained stable while comorbidities increased in the postperiod (table 2). In all cohorts, there was a marked increase in the percentage of individuals treated in hospitals that were accredited primary stroke centres or participating in a quality improvement programme for acute stroke care. County level characteristics generally remained stable from the preperiod to postperiod. Two notable exceptions to this trend were average unemployment rate and per cent of persons in poverty, which increased in all cohorts from the preperiod to postperiod. Similarly, median household income fell in the postperiod for all cohorts.

The county level race and ethnicity demographics remained stable across time for all cohorts.

\section{Regression results}

The marginal effect for the interaction term between the $\mathrm{AF}$ cohort and the postperiod represents the difference-in-difference estimate (table 3). Compared with the positive control cohort, the OAT initiation rate increased on average 10-percentage points $(p<0.01)$ for the $\mathrm{AF}$ cohort in the postperiod. Controlling for patient and hospital facility characteristics, this increase in OAT initiation remained significant (11-percentage point increase, $\mathrm{p}<0.01)$. Compared to the positive control cohort, the rate of OAT initiation was not significantly different in the negative control cohort. Oldest individuals ( $\geq 71$ years) and those with the highest number of comorbid conditions were less likely to initiate OAT. Being at greater risk of acute ischaemic stroke (by CHADS2 score) was not associated with greater OAT initiation. Greater number of outpatient primary care physicians claim preceding entry into the cohort was associated with increased OAT initiation. Finally, residential distance from the admitting hospital was negatively associated with OAT initiation.

\section{Sensitivity test results}

In sensitivity analyses (table 4), the difference-indifference estimate for the $\mathrm{AF}$ group was robust to alternate definitions of OAT initiation. The combined pharmacy claims, blood laboratory test and anticoagulation management definition of OAT initiation yielded a similar marginal effect of a nine-percentage point increase $(p<0.05)$ in OAT initiation for the treatment group compared with the positive control cohort in the postperiod. The marginal effect was smaller and nonsignificant in the blood laboratory test and

Table 1 Proportion of cohort initiating oral anticoagulation therapy in preperiod and postperiod

\begin{tabular}{|c|c|c|c|c|c|c|}
\hline \multirow{2}{*}{ Cohort } & \multicolumn{2}{|c|}{ Preperiod } & \multicolumn{2}{|c|}{ Postperiod } & \multirow[b]{2}{*}{ Difference } & \multirow[b]{2}{*}{ p Value } \\
\hline & $\overline{\mathbf{N}}$ & Proportion & $\overline{\mathbf{N}}$ & Proportion & & \\
\hline Eligible AF & 1359 & 0.268 & 662 & 0.317 & 0.049 & 0.022 \\
\hline Positive control & 1597 & 0.675 & 1111 & 0.620 & -0.055 & 0.003 \\
\hline Negative control & 302 & 0.238 & 204 & 0.206 & -0.032 & 0.398 \\
\hline \multicolumn{5}{|c|}{ Difference-in-difference estimate (AF-positive control) } & 0.104 & \\
\hline \multicolumn{5}{|c|}{ Difference-in-difference estimate (AF-negative control) } & 0.081 & \\
\hline
\end{tabular}




\begin{tabular}{|c|c|c|c|c|c|c|}
\hline \multirow[b]{2}{*}{ Variable } & \multicolumn{3}{|l|}{ Preperiod } & \multicolumn{3}{|l|}{ Postperiod } \\
\hline & Eligible AF & $\begin{array}{l}\text { Mechanical heart } \\
\text { valve (+ control) }\end{array}$ & PAF (- control) & Eligible AF & $\begin{array}{l}\text { Mechanical heart } \\
\text { valve (+ Control) }\end{array}$ & PAF (- Control) \\
\hline Sample size & 1359 & 1597 & 302 & 662 & 1111 & 204 \\
\hline \multicolumn{7}{|l|}{ Patient characteristics } \\
\hline Age & $77.9(11.2)$ & $65.0(15.7)$ & $71.2(12.9)$ & 76.7 (11.3) & $65.4(15.3)$ & $70.6(12.6)$ \\
\hline Male & 40.5 & 41.3 & 53.3 & 38.7 & 40.8 & 57.4 \\
\hline Rural & 9.7 & 10.2 & 9.3 & 12.3 & 10.5 & 11.8 \\
\hline $\mathrm{CHF}$ & 29.7 & 18.8 & 32.5 & 23.0 & 27.1 & 34.3 \\
\hline Hypertension & 94.7 & 68.1 & 82.8 & 96.2 & 76.8 & 85.8 \\
\hline Diabetes mellitus & 45.3 & 26.5 & 39.4 & 45.5 & 35.2 & 39.7 \\
\hline Ischaemic stroke & 23.7 & 18.8 & 21.5 & 35.5 & 31.1 & 29.4 \\
\hline CHADS2 score & $2.9(1.0)$ & $1.8(1.5)$ & $2.4(1.5)$ & $3.0(1.1)$ & $2.3(1.7)$ & $2.6(1.6)$ \\
\hline Charlson index & $2.0(1.7)$ & $1.4(1.6)$ & $2.3(2.0)$ & $2.1(1.7)$ & $1.9(2.0)$ & $2.7(2.3)$ \\
\hline Haemorrhagic stroke & 0 & 1.8 & 0.7 & 0 & 1.6 & 2 \\
\hline Gastrointestinal bleed & 0 & 4.1 & 2.0 & 0 & 8.5 & 5.4 \\
\hline Falls risk & 0 & 7.5 & 8.9 & 0 & 13.8 & 7.4 \\
\hline Cirrhosis & 0 & 2.9 & 2 & 0 & 5.3 & 4.9 \\
\hline Dementia & 0 & 1.8 & 2.3 & 0 & 2.3 & 2.5 \\
\hline Terminal illness & 0 & 7.4 & 6.3 & 0 & 7.5 & 6.9 \\
\hline Relative OAT contraindications & $0^{*}$ & $0.5(0.7)$ & $0.4(0.7)$ & $0^{*}$ & $0.7(0.9)$ & $0.6(0.9)$ \\
\hline Outpatient visits & $3.1(3.6)$ & $4.1(6.1)$ & $4.0(7.2)$ & $3.5(3.6)$ & $4.8(5.6)$ & $4.0(5.5)$ \\
\hline \multicolumn{7}{|l|}{ Facility characteristics } \\
\hline Rural hospital & 4.7 & 4.4 & 2.4 & 5.8 & 6.0 & 3.1 \\
\hline Primary stroke centre & 19.2 & 21.7 & 31.1 & 45.8 & 43.8 & 50.5 \\
\hline Participates in GWTG & 48.6 & 50.5 & 47.4 & 59.2 & 56.3 & 63.7 \\
\hline Hospital bed size & $449(311)$ & $464(309)$ & $525(322)$ & $461(307)$ & $460(310)$ & $506(324)$ \\
\hline Distance residence hospital (miles) & $21.7(82.2)$ & $23.9(76.7)$ & $22.9(57.9)$ & $20.1(48.0)$ & $18.4(53.4)$ & $18.5(28.7)$ \\
\hline \multicolumn{7}{|l|}{ County characteristics } \\
\hline Caucasian (\%) & $68.9(15.3)$ & $68.3(15.0)$ & $68.5(14.5)$ & $68.5(15.1)$ & $68.7(15.0)$ & $67.6(15.2)$ \\
\hline Per cent African-American (\%) & $21.4(13.2)$ & $21.8(13.2)$ & $21.6(12.6)$ & $22.0(13.3)$ & $21.4(13.3)$ & $22.5(14.2)$ \\
\hline Per cent American Indian & $1.4(5.2)$ & $1.5(5.2)$ & $1.4(4.8)$ & $1.3(4.7)$ & $1.5(5.1)$ & $1.2(2.0)$ \\
\hline Asian & $2.0(1.9)$ & $2.2(2.0)$ & $2.2(2.0)$ & $1.9(1.9)$ & $2.1(2.0)$ & $2.2(2.0)$ \\
\hline Hispanic & $7.9(3.6)$ & $8.0(3.7)$ & $8.0(3.3)$ & $8.0(3.7)$ & $8.1(3.6)$ & $8.3(4.4)$ \\
\hline General practitioners & $62.6(67.8)$ & $68.1(72.1)$ & $73.5(76.1)$ & $68.4(79.8)$ & $73.5(87.0)$ & $73.6(80.9)$ \\
\hline Cardiovascular specialists & $17.0(21.6)$ & $18.6(22.9)$ & $20.7(24.2)$ & $17.6(23.2)$ & $19.4(24.8)$ & $19.6(23.7)$ \\
\hline 3 year average death cerebrovascular disease & $106.5(90.0)$ & $113.2(96.8)$ & $119.3(101.3)$ & $107.0(91.7)$ & $112.7(105)$ & $108.7(93.7)$ \\
\hline County Median Hhld income (1000s) & $44.6(9.4)$ & $45.1(9.6)$ & $46.6(10.2)$ & $43.5(9.6)$ & $44.7(10.0)$ & $44.7(10.5)$ \\
\hline Unemployment rate & $5.2(1.4)$ & $5.4(1.5)$ & $5.5(1.7)$ & $10.7(2.1)$ & $10.7(2.1)$ & $10.5(2.3)$ \\
\hline
\end{tabular}

*Inclusion in AF treatment group conditional on value of zero for this variable.

(), SD.

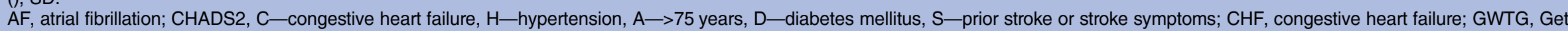

With The Guidelines; OAT, oral anticoagulation therapy; PAF, paroxysmal atrial fibrillation. 
Table 3 Estimated marginal effects of policy changes, patient characteristics and inpatient facility characteristics on oral anticoagulation therapy initiation

\begin{tabular}{|c|c|c|c|c|}
\hline & \multicolumn{2}{|c|}{ Adjusted for patient characteristics } & \multicolumn{2}{|c|}{$\begin{array}{l}\text { Adjusted for patient and facility } \\
\text { characteristics }\end{array}$} \\
\hline \multicolumn{5}{|l|}{ Adjusted results } \\
\hline Postperiod & $-0.04^{*}$ & $(-0.07$ to -0.01$)$ & $-0.03^{*}$ & $(-0.06$ to -0.00$)$ \\
\hline Treatment group & $-0.39^{\star \star \star}$ & $(-0.43$ to -0.35$)$ & $-0.38^{* \star *}$ & $(-0.42$ to -0.34$)$ \\
\hline Negative control & $-0.45^{\star \star \star}$ & $(-0.54$ to -0.36$)$ & $-0.45^{\star \star \star}$ & $(-0.54$ to -0.36$)$ \\
\hline Post-treatment & $0.10^{\star \star}$ & $(0.04$ to 0.17$)$ & $0.11^{\star *}$ & (0.04 to 0.18$)$ \\
\hline Post-negative control & -0.03 & $(-0.19$ to 0.13$)$ & -0.03 & $(-0.19$ to 0.13$)$ \\
\hline \multicolumn{5}{|l|}{ Patient characteristics } \\
\hline $18-40$ years & 0.03 & $(-0.03$ to 0.09$)$ & 0.03 & $(-0.02$ to 0.09$)$ \\
\hline $61-70$ years & -0.01 & $(-0.04$ to 0.02$)$ & -0.01 & $(-0.04$ to 0.02$)$ \\
\hline $71+$ years & $-0.10^{\star \star *}$ & $(-0.13$ to -0.07$)$ & $-0.10^{\star * *}$ & $(-0.14,-0.07)$ \\
\hline Gender (male) & $0.02^{*}$ & $(0.00$ to 0.04$)$ & $0.03^{\star \star}$ & (0.01 to 0.05$)$ \\
\hline Charlson (0) & 0.01 & $(-0.03$ to 0.06$)$ & 0.01 & $(-0.03$ to 0.05$)$ \\
\hline Charlson (2) & $-0.04^{*}$ & $(-0.07$ to -0.00$)$ & $-0.04^{*}$ & $(-0.07$ to -0.00$)$ \\
\hline Charlson (3-4) & -0.02 & $(-0.06$ to 0.03$)$ & -0.01 & $(-0.06$ to 0.03$)$ \\
\hline Charlson $(5+)$ & $-0.13^{\star \star \star}$ & $(-0.17$ to -0.09$)$ & $-0.12^{\star \star \star}$ & $(-0.17$ to -0.08$)$ \\
\hline CHADS2 (0-1) & -0.02 & $(-0.05$ to 0.02$)$ & -0.01 & $(-0.05$ to 0.03$)$ \\
\hline CHADS2( 3-4) & $-0.05^{*}$ & $(-0.09$ to -0.01$)$ & $-0.04^{*}$ & $(-0.08$ to -0.00$)$ \\
\hline CHADS2 (5+) & -0.04 & $(-0.11$ to 0.04$)$ & -0.03 & $(-0.10$ to 0.04$)$ \\
\hline Rural & 0.02 & $(-0.03$ to 0.06$)$ & 0.01 & $(-0.05$ to 0.07$)$ \\
\hline Micropolitan & 0.01 & $(-0.03$ to 0.04$)$ & -0.00 & $(-0.05$ to 0.04$)$ \\
\hline 0 pre-event visits & $-0.05^{\star}$ & $(-0.09$ to -0.00$)$ & -0.04 & $(-0.09$ to 0.00$)$ \\
\hline $2+$ pre-event visits & $0.06^{\star * *}$ & (0.03 to 0.09$)$ & $0.05^{\star \star \star}$ & $(0.02$ to 0.08$)$ \\
\hline \multicolumn{5}{|l|}{ Facility characteristics } \\
\hline Primary stroke centre & & & -0.01 & $(-0.06$ to 0.04$)$ \\
\hline GWTG participation & & & -0.01 & $(-0.03$ to 0.02$)$ \\
\hline 4-99 beds & & & -0.04 & $(-0.09$ to 0.00$)$ \\
\hline $500+$ beds & & & -0.04 & $(-0.08$ to 0.00$)$ \\
\hline $25+$ miles & & & $-0.10^{\star * *}$ & $(-0.16$ to -0.05$)$ \\
\hline Rural provider & & & 0.07 & $(-0.01$ to 0.16$)$ \\
\hline Micropolitan provider & & & 0.04 & $(-0.01$ to 0.09$)$ \\
\hline Observations & 5235 & & 5235 & \\
\hline \multicolumn{5}{|l|}{$\begin{array}{l}95 \% \text { Cls in parenthesis. } \\
{ }^{*} p<0.05 . \\
\star \star * \\
{ }^{\star \star \star} p<0.01\end{array}$} \\
\hline
\end{tabular}

anticoagulation management only definition of OAT initiation. Other associations were similar to that observed in the primary analysis. We also found a strong marginal effect on OAT initiation for an outpatient-only intervention cohort and the combined inpatient-outpatient cohort. Finally, multiple model specifications with alternate functional form and additional control covariates resulted in similar findings as our primary analysis (see web-only table A.5).

\section{DISCUSSION}

We examined the association between the Joint Commission revising NPSGs and OAT initiation among privately insured individuals with new onset AF. Compared with the positive control cohort, the revised Joint Commission NPSGs were associated with a 10-percentage point increase in the rate of OAT initiation among individuals with new onset AF. The negative association between age and OAT initiation as well as number of comorbidities and OAT initiation are consistent with what has been previously described in the literature. ${ }^{45}$ The relative lack of association of increasing CHADS2 scores and OAT initiation is also consistent with prior work and is hypothesised to be secondary to increased comorbidities associated with increasing CHADS2 score that may discourage a clinician from initiating OAT. ${ }^{46}$

The strong positive association between NPSGs and the outpatient cohort in our sensitivity analysis suggest an indirect effect of NPSGs as well. The rate of OAT initiation in the positive control cohort was smaller than anticipated, and decreased between preperiod and postperiod.

The relatively low-OAT initiation in the positive control (perceived very high risk) cohort and the 
Table 4 Estimated marginal effects of sensitivity analyses in alternate outcome definitions, outpatient only cohort and combined inpatient/outpatient cohorts

\begin{tabular}{|c|c|c|c|c|c|c|c|c|}
\hline \multirow[b]{2}{*}{$18-40$ years } & \multicolumn{2}{|c|}{$\begin{array}{l}\text { OAT-RX and } \\
\text { OAT-laboratories }\end{array}$} & \multicolumn{2}{|c|}{ OAT-laboratories } & \multicolumn{2}{|c|}{ OAT-outpatients } & \multicolumn{2}{|l|}{ OAT-all } \\
\hline & 0.01 & $(-0.04$ to 0.07$)$ & 0.01 & $(-0.03$ to 0.06$)$ & -0.02 & $(-0.07$ to 0.03$)$ & 0.01 & $(-0.03$ to 0.04$)$ \\
\hline $61-70$ years & -0.02 & $(-0.04$ to 0.01$)$ & $-0.18^{\star \star \star}$ & $(-0.21$ to -0.14$)$ & 0.02 & $(-0.01$ to 0.06$)$ & 0.01 & $(-0.02$ to 0.04$)$ \\
\hline $71+$ years & $-0.12^{\star \star \star}$ & $(-0.16$ to -0.09$)$ & $-0.38^{\star \star \star}$ & $(-0.43$ to -0.34$)$ & $-0.05^{\star}$ & $(-0.09$ to -0.01$)$ & $-0.09^{\star \star \star}$ & $(-0.11$ to -0.06$)$ \\
\hline Gender (male) & 0.02 & $(-0.00$ to 0.04$)$ & 0.01 & $(-0.01$ to 0.03$)$ & $0.06^{\star \star *}$ & (0.03 to 0.08$)$ & $0.04^{\star \star \star}$ & $(0.02$ to 0.06$)$ \\
\hline Charlson (0) & 0.02 & $(-0.02$ to 0.06$)$ & 0.03 & $(-0.00$ to 0.05$)$ & 0.03 & $(-0.01$ to 0.07$)$ & 0.01 & $(-0.01$ to 0.04$)$ \\
\hline Charlson (2) & -0.03 & $(-0.06$ to 0.01$)$ & -0.02 & $(-0.05$ to 0.01$)$ & -0.04 & $(-0.08$ to 0.01$)$ & $-0.05^{\star \star}$ & $(-0.08$ to -0.01$)$ \\
\hline Charlson (3-4) & -0.00 & $(-0.05$ to 0.04$)$ & $-0.04^{*}$ & $(-0.07$ to -0.00$)$ & -0.05 & $(-0.09$ to 0.00$)$ & $-0.05^{\star \star}$ & $(-0.08$ to -0.01$)$ \\
\hline Charlson (5+) & $-0.12^{\star \star \star}$ & $(-0.16$ to -0.07$)$ & $-0.07^{\star \star \star}$ & $(-0.11$ to -0.03$)$ & $-0.11^{\star \star \star}$ & $(-0.17$ to -0.05$)$ & $-0.13^{\star \star \star}$ & $(-0.17$ to -0.09$)$ \\
\hline CHADS2 (0-1) & -0.00 & $(-0.04$ to 0.04$)$ & 0.02 & $(-0.01$ to 0.05$)$ & 0.02 & $(-0.02$ to 0.06$)$ & 0.00 & $(-0.03$ to 0.03$)$ \\
\hline CHADS2( 3-4) & $-0.04^{\star}$ & $(-0.08$ to -0.00$)$ & -0.01 & $(-0.03$ to 0.02$)$ & -0.01 & $(-0.05$ to 0.03$)$ & $-0.03^{\star}$ & $(-0.05$ to -0.00$)$ \\
\hline CHADS2 (5+) & -0.02 & $(-0.08$ to 0.04$)$ & -0.04 & $(-0.10$ to 0.02$)$ & -0.04 & $(-0.10$ to 0.03$)$ & -0.04 & $(-0.09$ to 0.01$)$ \\
\hline Rural & -0.00 & $(-0.07$ to 0.06$)$ & $-0.04^{\star}$ & $(-0.08$ to -0.01$)$ & -0.05 & $(-0.11$ to 0.01$)$ & -0.03 & $(-0.07$ to 0.01$)$ \\
\hline Micropolitan & -0.01 & $(-0.06$ to 0.04$)$ & $-0.03^{\star \star}$ & $(-0.05$ to -0.01$)$ & 0.00 & $(-0.05$ to 0.05$)$ & -0.01 & $(-0.04$ to 0.02$)$ \\
\hline Postperiod & -0.02 & $(-0.05$ to 0.01$)$ & $0.03^{\star \star}$ & $(0.01$ to 0.05$)$ & 0.01 & $(-0.02$ to 0.04$)$ & -0.01 & $(-0.03$ to 0.01$)$ \\
\hline Treatment group & $-0.38^{\star \star \star}$ & $(-0.42$ to -0.34$)$ & $-0.14^{\star \star \star}$ & $(-0.18$ to -0.10$)$ & $-0.44^{\star \star \star}$ & $(-0.50$ to -0.39$)$ & $-0.42^{\star \star \star}$ & $(-0.46$ to -0.38$)$ \\
\hline Post-treatment & $0.09^{*}$ & $(0.02$ to 0.16$)$ & 0.03 & $(-0.03$ to 0.09$)$ & $0.17^{\star \star \star}$ & (0.09 to 0.25$)$ & $0.14^{* * *}$ & (0.08 to 0.19$)$ \\
\hline Negative control & $-0.44^{\star \star \star}$ & $(-0.53$ to -0.36$)$ & $-0.21^{\star \star \star}$ & $(-0.27$ to -0.15$)$ & $-0.49^{\star \star \star}$ & $(-0.64$ to -0.34$)$ & $-0.49^{\star \star \star}$ & $(-0.57$ to -0.40$)$ \\
\hline Post-negative control & -0.03 & $(-0.19$ to 0.13$)$ & -0.02 & $(-0.11$ to 0.08$)$ & 0.09 & $(-0.10$ to 0.29$)$ & 0.02 & $(-0.10$ to 0.14$)$ \\
\hline 0 prediagnosis visits & $-0.05^{\star}$ & $(-0.09$ to -0.00$)$ & $-0.06^{\star \star \star}$ & $(-0.10$ to -0.03$)$ & $0.09^{* *}$ & $(0.03$ to 0.14$)$ & 0.02 & $(-0.01$ to 0.06$)$ \\
\hline $2+$ prediagnosis visits & $0.05^{\star \star \star}$ & $(0.02$ to 0.08$)$ & $0.04^{\star \star *}$ & (0.02 to 0.07$)$ & $0.08^{\star \star \star}$ & (0.04 to 0.12$)$ & $0.06^{\star * \star}$ & (0.03 to 0.08$)$ \\
\hline Primary stroke centre & -0.01 & $(-0.06$ to 0.04$)$ & -0.02 & $(-0.05$ to 0.00$)$ & & & & \\
\hline GWTG participation & -0.01 & $(-0.04$ to 0.01$)$ & -0.00 & $(-0.03$ to 0.02$)$ & & & & \\
\hline 4-99 beds & $-0.04^{\star}$ & $(-0.09$ to -0.00$)$ & 0.01 & $(-0.02$ to 0.04$)$ & & & & \\
\hline $500+$ beds & -0.03 & $(-0.07$ to 0.01$)$ & -0.01 & $(-0.05$ to 0.03$)$ & & & & \\
\hline 25+ miles & $-0.10^{\star \star \star}$ & $(-0.15$ to -0.05$)$ & $-0.04^{\star \star \star}$ & $(-0.06$ to -0.02$)$ & & & & \\
\hline Rural provider & 0.08 & $(-0.00$ to 0.17$)$ & 0.05 & $(-0.01$ to 0.10$)$ & $0.12^{\star \star}$ & (0.04 to 0.20$)$ & $0.11^{\star \star *}$ & (0.05 to 0.17$)$ \\
\hline Micropolitan provider & $0.05^{\star}$ & (0.00 to 0.09$)$ & $0.04^{\star}$ & (0.00 to 0.08$)$ & 0.01 & $(-0.04$ to 0.06$)$ & $0.04^{\star}$ & (0.01 to 0.07 ) \\
\hline Inpt Index Claim & & & & & & & $-0.03^{\star \star}$ & $(-0.05$ to -0.01$)$ \\
\hline Observations & 5235 & & 5235 & & 4694 & & 9380 & \\
\hline
\end{tabular}

$95 \%$ Cls in parentheses.

${ }^{*} p<0.05$.

${ }^{* *} p<0.01$.

${ }^{* * *} \mathrm{p}<0.001$.

CHADS2, C—congestive heart failure, H—hypertension, A $\rightarrow 75$ years, D—diabetes mellitus, S—prior stroke or stroke symptoms; GWTG, Get With The Guidelines; Inpt, inpatient; OAT, oral anticoagulation therapy; RX, prescription. 
intervention cohort, as well as the higher than expected OAT initiation in the negative control (perceived low risk) cohort, are interesting. This finding may reflect the nature of health insurance claims data, which may miss prescription claims (especially given the availability of low-cost mediations at retail stores). However, our measured rates of OAT initiation in the AF cohort are consistent with prior studies. ${ }^{44}$ While we believe underutilisation of OAT among incident AF and paroxysmal AF patients is evident in our findings, this underutilisation should be reported with caution given the inherent limitations of using claims data. We view our results, not as an indictment suggesting poor quality of care for new onset $\mathrm{AF}$, but rather as an examination of positive trends in guideline concordant care for patients with incident $\mathrm{AF}$ following policy change, and an absence of unintended negative effects on care. We also note that the rate of anticoagulation observed in the positive control may represent a realistic target rate for incident $\mathrm{AF}$ and patients with paroxysmal $\mathrm{AF}$ when using claims data.

The study has several strengths. First, the use of perceived very high-risk and perceived low-risk control groups allow for greater mitigation of potential time bias between the preperiod and postperiod that is common in observational studies. We are not aware of published OAT initiation rates for individuals with mechanical heart valves or significant thromboembolism. Using this group as a benchmark sheds new light on previous observational studies. Second, using a statewide claims database with approximately one million privately insured state workers, spouses, dependents and retirees increases the generalisability of our findings. Third, linking with the Area Resource File and OSCAR databases provides a rich array of county and hospital facility control variables, respectively. Fourth, we included multiple controls for comorbid conditions and relative contraindications to OAT. Finally, the clustering of individuals within the hospital in which they received treatment mitigates potential effects of outlier hospitals on the population-averaged effect of the policy change. ${ }^{40}$

There are several limitations of our study. First, we used a quasi-experimental observational study design. Without randomisation, we cannot eliminate threats to internal validity such as regression to the mean, history and instrumentation. For example, unmeasured differences in all cohorts between preperiod and postperiod may have confounded our findings. Second, because we used claims data, we may have misclassified OAT initiation, especially with the popularity of low-cost generic OAT that could be purchased without billing the insurer. ${ }^{43}$ We have no reason to suspect differential bias in pharmacy claims for warfarin across the three cohorts regarding OAT initiation. Furthermore, if present, this trend may increase with time, which would bias OAT initiation downwards in the postperiod; this may help explain the slight decrease in OAT initiation among the guideline-positive cohort. Importantly, our sensitivity analyses suggested that findings were robust to alternative definitions of OAT initiation. Third, we could not control for individual level race, ethnicity or socioeconomic status. However, we controlled for county level indicators of race and socioeconomic status to mitigate these potential effects. Fourth, most members of our cohorts had employee-sponsored group health insurance; results may not generalise to publicly insured populations. Notably, our cohorts included a large proportion of retired Medicare enrollees utilising both their Medicare and NCSHP benefits, which serves to enhance generalisability to Medicare beneficiaries. Finally, new medications for OAT were approved for reduction of stroke risk in patients with AF in late 2010. We purposely limited our study window to exclude these medications which, while more expensive than warfarin, do not require the same frequency of laboratory monitoring and titration of dosage.

\section{CONCLUSION}

Our findings show that following NPSGs concerning anticoagulation, lower rates of anticoagulation among incident eligible patients with AF were not observed. Rather when compared with control groups which declined in the rate of anticoagulation, rates of anticoagulation increased among eligible patients with incident AF. OAT initiation should be re-examined with additional years of data, broader geographic representation and the inclusion of novel anticoagulation agents to support or refute our findings. Our work demonstrates the direct (in primary analysis of patients with incident inpatient diagnosed $\mathrm{AF}$ ) and indirect (in sensitivity analysis of patients with incident outpatient diagnosed AF) changes in anticoagulation practice co-occurring with changes in policies of healthcare regulatory agencies via patient safety and quality improvement initiatives.

\section{Author affiliations}

${ }^{1}$ Cecil G. Sheps Center for Health Services Research, University of North Carolina at Chapel Hill, Durham, North Carolina, USA

${ }^{2}$ Department of Health Policy and Management, Gillings School of Global Public Health, University of North Carolina at Chapel Hill, Chapel Hill, North Carolina, USA

${ }^{3}$ Department of Veterans Affairs Medical Center, Center for Health Services Research in Primary Care, Durham, North Carolina, USA

${ }^{4}$ Department of Family Medicine, University of North Carolina at Chapel Hill, Chapel Hill, North Carolina, USA

${ }^{5}$ Department of Epidemiology, Gillings School of Global Public Health, University of North Carolina at Chapel Hill, Chapel Hill, North Carolina, USA

Contributors $\mathrm{CAB}, \mathrm{MW}, \mathrm{AJV}, \mathrm{SBG}, \mathrm{MAB}$ and $\mathrm{KH}-\mathrm{L}$ were involved in all aspects of manuscript including: the conception and design, analysis and interpretation of data, drafting the article or revising it critically for important intellectual content and final approval of the version to be published.

Funding AHRQ: 1T32 HS019442 and VA Office of Academic Affiliations Post-doctoral fellowship (TPP 21-023).

Competing interests None.

Ethics approval University of North Carolina Chapel Hill. The study protocol was approved by the University Institutional Review Board. 
Provenance and peer review Not commissioned; externally peer reviewed.

Data sharing statement The data are available through Carolina Cost and Quality Initiative (CCQI) managed by the Cecil G. Sheps Center for Health Services Research. Their website includes additional information on cost and data use agreements.

Open Access This is an Open Access article distributed in accordance with the Creative Commons Attribution Non Commercial (CC BY-NC 3.0) license, which permits others to distribute, remix, adapt, build upon this work noncommercially, and license their derivative works on different terms, provided the original work is properly cited and the use is non-commercial. See: http:// creativecommons.org/licenses/by-nc/3.0/

\section{REFERENCES}

1. ACCP. 4th American College of Chest Physicians Consensus Conference on Antithrombotic Therapy. Tucson, Arizona, April 1995 Proceedings. Chest 1995;108(4 Suppl):225S-522S.

2. Beyth RJ, Antani MR, Covinsky KE, et al. Why isn't warfarin prescribed to patients with nonrheumatic atrial fibrillation? J Gen Intern Med 1996;11:721-8.

3. Antani MR, Beyth RJ, Covinsky KE, et al. Failure to prescribe warfarin to patients with nonrheumatic atrial fibrillation. $J$ Gen Intern Med 1996;11:713-20.

4. Harley CR, Riedel AA, Hauch O, et al. Anticoagulation therapy in patients with chronic atrial fibrillation: a retrospective claims data analysis. Curr Med Res Opin 2005;21:215-22.

5. Albers GW, Bittar N, Young $\mathrm{L}$, et al. Clinical characteristics and management of acute stroke in patients with atrial fibrillation admitted to US university hospitals. Neurology 1997;48:1598-604.

6. Go AS, Hylek EM, Borowsky LH, et al. Warfarin use among ambulatory patients with nonvalvular atrial fibrillation: the anticoagulation and risk factors in atrial fibrillation (ATRIA) study. Ann Intern Med 1999;131:927-34.

7. Gage BF, Boechler M, Doggette AL, et al. Adverse outcomes and predictors of underuse of antithrombotic therapy in medicare beneficiaries with chronic atrial fibrillation. Stroke 2000;31:822-7.

8. Allen LaPointe NM, Governale L, Watkins J, et al. Outpatient use of anticoagulants, rate-controlling drugs, and antiarrhythmic drugs for atrial fibrillation. Am Heart $J$ 2007; 154:893-8.

9. Johnston JA, Cluxton RJ Jr, Heaton PC, et al. Predictors of warfarin use among Ohio medicaid patients with new-onset nonvalvular atria fibrillation. Arch Intern Med 2003;163:1705-10.

10. Choudhry NK, Soumerai SB, Normand SL, et al. Warfarin prescribing in atrial fibrillation: the impact of physician, patient, and hospital characteristics. Am J Med 2006;119:607-15.

11. Orensky IA, Holdford DA. Predictors of noncompliance with warfarin therapy in an outpatient anticoagulation clinic. Pharmacotherapy 2005;25:1801-8.

12. Bungard TJ, Ghali WA, McAlister FA, et al. The relative importance of barriers to the prescription of warfarin for nonvalvular atrial fibrillation. Can J Cardiol 2003;19:280-4.

13. Dantas GC, Thompson BV, Manson JA, et al. Patients' perspectives on taking warfarin: qualitative study in family practice. BMC Fam Pract 2004;5:15.

14. Buckingham TA, Hatala R. Anticoagulants for atrial fibrillation: why is the treatment rate so low? Clin Cardiol 2002;25:447-54.

15. Lane DA, Lip GY. Barriers to anticoagulation in patients with atrial fibrillation: changing physician-related factors. Stroke 2008;39:7-9.

16. Commission TJ. About the Joint Commission Secondary about the Joint Commission. 2012. http://www.jointcommission.org/about_us/ about_the_joint_commission_main.aspx

17. Bungard TJ, Ghali WA, Teo KK, et al. Why do patients with atrial fibrillation not receive warfarin? Arch Intern Med 2000;160:41-6.

18. Doran T, Fullwood C, Gravelle $\mathrm{H}$, et al. Pay-for-performance programs in family practices in the United Kingdom. N Engl $\mathrm{J} \mathrm{Med}$ 2006;355:375-84.

19. Roland M. Pay-for-performance: too much of a good thing? A conversation with Martin Roland. Interview by Robert Galvin. Health Aff (Millwood) 2006;25:w412-19.

20. Chen TT, Chung KP, Lin IC, et al. The unintended consequence of diabetes mellitus pay-for-performance (P4P) program in Taiwan: are patients with more comorbidities or more severe conditions likely to be excluded from the P4P program? Health Serv Res 2011; 46(1 Pt 1):47-60.

21. Werner RM, Konetzka RT, Kruse GB. Impact of public reporting on unreported quality of care. Health Serv Res 2009;44(2 Pt 1):379-98.
22. Mehrotra A, Hussey PS, Milstein A, et al. Consumers' and providers' responses to public cost reports, and how to raise the likelihood of achieving desired results. Health Aff (Millwood) 2012;31:843-51.

23. Resnic FS, Welt FG. The public health hazards of risk avoidance associated with public reporting of risk-adjusted outcomes in coronary intervention. J Am Coll Cardiol 2009;53:825-30.

24. Stone PW, Pogorzelska M, Graham D, et al. California hospitals response to state and federal policies related to health care-associated infections. Policy Polit Nurs Pract 2011;12:73-81.

25. VanSuch M, Naessens JM, Stroebel RJ, et al. Effect of discharge instructions on readmission of hospitalised patients with heart failure: do all of the Joint Commission on Accreditation of Healthcare Organizations heart failure core measures reflect better care? Qual Saf Health Care 2006:15:414-17.

26. Kfoury AG, French TK, Horne BD, et al. Incremental survival benefit with adherence to standardized heart failure core measures: a performance evaluation study of 2958 patients. J Card Fail 2008;14:95-102.

27. Patterson ME, Hernandez AF, Hammill BG, et al. Process of care performance measures and long-term outcomes in patients hospitalized with heart failure. Med Care 2010;48:210-16.

28. Fonarow GC, Abraham WT, Albert NM, et al. Association between performance measures and clinical outcomes for patients hospitalized with heart failure. JAMA 2007;297:61-70.

29. Goldstein LB, Adams R, Alberts MJ, et al. Primary prevention of ischemic stroke: a guideline from the American Heart Association/ American Stroke Association Stroke Council: cosponsored by the Atherosclerotic Peripheral Vascular Disease Interdisciplinary Working Group; Cardiovascular Nursing Council; Clinical Cardiology Council; Nutrition, Physical Activity, and Metabolism Council; and the Quality of Care and Outcomes Research Interdisciplinary Working Group. Circulation 2006;113:e873-923.

30. Go AS, Mozaffarian D, Roger VL, et al. Heart disease and stroke statistics-2013 update: a report from the American Heart Association. Circulation 2013;127:e6-245.

31. Goldstein LB, Bushnell CD, Adams RJ, et al. Guidelines for the primary prevention of stroke: a guideline for healthcare professionals from the American Heart Association/American Stroke Association. Stroke 2011:42:517-84.

32. Aboaf AP, Wolf PS. Paroxysmal atrial fibrillation. A common but neglected entity. Arch Intern Med 1996;156:362-7.

33. Petersen P, Godtfredsen J. Embolic complications in paroxysmal atrial fibrillation. Stroke 1986;17:622-6.

34. Hart RG, Pearce LA, Rothbart RM, et al. Stroke with intermittent atrial fibrillation: incidence and predictors during aspirin therapy. Stroke prevention in atrial fibrillation investigators. J Am Coll Cardiol 2000;35:183-7.

35. van Walraven C, Hart RG, Singer DE, et al. Oral anticoagulants vs aspirin in nonvalvular atrial fibrillation: an individual patient meta-analysis. JAMA 2002;288:2441-8.

36. Gage BF, Waterman AD, Shannon W, et al. Validation of clinical classification schemes for predicting stroke: results from the National Registry of Atrial Fibrillation. JAMA 2001;285:2864-70.

37. Charlson ME, Pompei P, Ales KL, et al. A new method of classifying prognostic comorbidity in longitudinal studies: development and validation. J Chronic Dis 1987;40:373-83.

38. Deyo RA, Cherkin DC, Ciol MA. Adapting a clinical comorbidity index for use with ICD-9-CM administrative databases. J Clin Epidemiol 1992;45:613-19.

39. HRSA. Area Resource File (ARF). 2011-2012. Rockville, MD: US Department of Health and Human Services, Health Resources and Services Administration, Bureau of Health Professions, 2012.

40. Localio AR, Berlin JA, Ten Have TR, et al. Adjustments for center in multicenter studies: an overview. Ann Intern Med 2001;135:112-23.

41. Zou G. A modified poisson regression approach to prospective studies with binary data. Am J Epidemiol 2004;159:702-6.

42. Shrank WH, Choudhry NK. Time to fill the doughnuts-health care reform and Medicare Part D. N Engl J Med 2011;364:598-601.

43. Lauffenburger JC, Balasubramanian A, Farley JF, et al. Completeness of prescription information in US commercial claims databases. Pharmacoepidemiol Drug Saf 2013;22:899-906.

44. Baczek VL, Chen WT, Kluger J, et al. Predictors of warfarin use in atrial fibrillation in the United States: a systematic review and meta-analysis. BMC Fam Pract 2012:13:5.

45. Pugh D, Pugh J, Mead GE. Attitudes of physicians regarding anticoagulation for atrial fibrillation: a systematic review. Age Ageing 2011;40:675-83.

46. Gallagher AM, Rietbrock S, Plumb J, et al. Initiation and persistence of warfarin or aspirin in patients with chronic atrial fibrillation in general practice: do the appropriate patients receive stroke prophylaxis? J Thromb Haemost 2008;6:1500-6. 